\title{
ChemComm
}

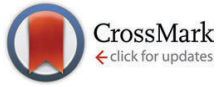

Cite this: Chem. Commun., 2014, 50, 13359

Received 23rd July 2014, Accepted 10th September 2014

DOI: $10.1039 / \mathrm{c} 4 \mathrm{cc} 05694 a$

www.rsc.org/chemcomm

\section{Photoinduced charge separation in ordered self-assemblies of perylenediimide-graphene oxide hybrid layers $\uparrow$}

\author{
Mustafa Supur, Kei Ohkubo and Shunichi Fukuzumi*
}

\begin{abstract}
Remarkably fast photoinduced charge separation in well-ordered self-assemblies of perylenediimide-graphene oxide (TAIPDI-GO) hybrid layers was observed in aqueous environments. Slow charge recombination indicates an effective charge migration between the self-assembled layers of PDI-GO hybrids following the charge separation.
\end{abstract}

Graphene oxide (GO), a chemically exfoliated graphene derivative, offers new composite materials for photochemical applications. ${ }^{1}$ Effective visible light harvesting on GO sheets has been achieved by decorating with appropriate organic dye molecules via non-covalent interactions with the $\pi$-surface of GO bearing oxygen-containing functional groups. Many hybrids of GO have been formed by employing various organic dyes with hydrophilic substituents (pyrenes, perylenes, porphyrins, coronenes, and semiconducting oligomers and polymers) in aqueous environments. ${ }^{1}$ The efforts have been, so far, concentrated on obtaining only single or a few dye-functionalised GO or graphene layers and their photoinduced events. ${ }^{2}$ The studies on the self-assemblies of the well-ordered dye-GO hybrid layers are still limited ${ }^{3}$ and photoinduced charge generation in these structures is yet to be studied.

In this communication, we report the formation of ordered self-assemblies of GO layers functionalised with $N, N^{\prime}$-di(2-(trimethylammoniumiodide) ethylene)perylenediimide (TAIPDI-GO, Fig. 1 and Fig. S1, ESI $\dagger$ ) and their photoinduced electron-transfer processes. Perylenediimide (PDI) is an ideal building block for nanohybrids of GO because its strong absorption in the visible region and the low reduction potential make it a powerful light harvester and a good electron acceptor during a possible photoinduced electron-transfer process with the GO sheet. ${ }^{4}$ TAIPDI bears cationic groups enhancing the electrostatic interactions with the functional groups of $\mathrm{GO}$, such as $-\mathrm{COOH}$, and its large aromatic plane establishes strong $\pi-\pi$ interactions with the

Department of Material and Life Science, Graduate School of Engineering, Osaka University, ALCA, Japan Science and Technology Agency (JST), Suita, Osaka 565-0871, Japan. E-mail: fukuzumi@chem.eng.osaka-u.ac.jp; Fax: +81-6-6879-7370; Tel: +81-6-6879-7368

$\dagger$ Electronic supplementary information (ESI) available. See DOI: 10.1039/c4cc05694a
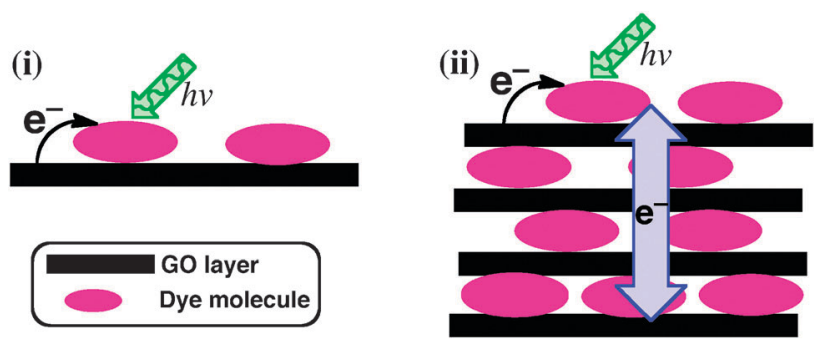

Fig. 1 (i) Photoinduced charge separation in single or a few layers of dye-GO hybrids examined in previous studies. (ii) Proposed photoinduced charge separation and interlayer charge migration in ordered self-assemblies of TAIPDI-GO hybrid layers investigated in this communication.

$\pi$-surface of the GO sheet. As a result of these interactions, TAIPDIGO hybrids are expected to form self-assembled organizations in water. Charge migration in the self-assembled layers of TAIPDI-GO following the initial electron-transfer from the GO sheet to closely interacting TAIPDI molecules is proposed upon the excitation of the TAIPDIs (Fig. 1).

Self-assembly of TAIPDIs with GO layers was first detected by UV-vis spectroscopy. Absorption maxima of PDI at 501 and $537 \mathrm{~nm}$ were shifted to 510 and $548 \mathrm{~nm}$, respectively. Hybrid formation also caused the quenching of TAIPDI fluorescence emission (Fig. 2). Significant spectral changes in the absorption of TAIPDI-GO and emission quenching indicate $\pi-\pi$ interactions between the
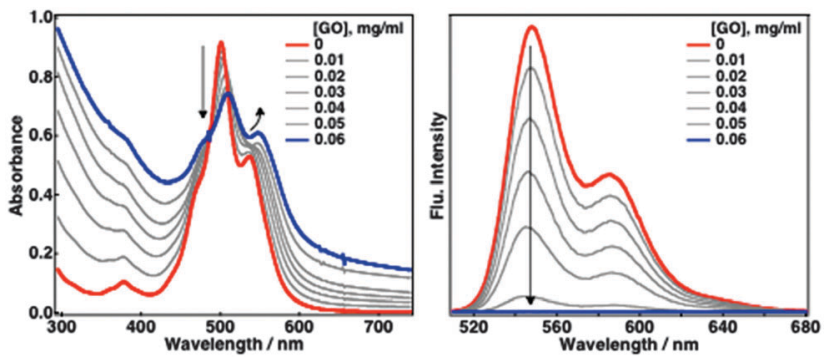

Fig. 2 Absorption (left) and fluorescence emission (right) spectral changes during the addition of GO to the aqueous solution of $0.025 \mathrm{mM}$ TAIPDI, $\lambda_{\text {exc }}=$ $510 \mathrm{~nm}$. 
$\pi$-surfaces of PDI and GO, which typically favours the photoinduced electron-transfer processes due to the very close distance as observed in the non-covalently functionalized carbon materials with large $\pi$-surfaces. ${ }^{2 g, 5}$

Self-assembly of TAIPDI-GO layers leads to supramolecular gel formation in water under mild conditions (see Experimental section and Fig. S2-S4, ESI $\dagger$ ). Apparently, cationic TAIPDI ${ }^{6}$ acts as a gelator, enhancing the $\pi-\pi$ stacking. Powder X-ray diffraction (PXRD) was utilized to analyze the structural organization in the self-assemblies. GO showed a sharp peak at $2 \theta=10.2^{\circ}$ correlated with a $d$-spacing of $8.66 \AA$ between the GO layers, which is very close to previously reported values. ${ }^{3}$ Incorporation of TAIPDI molecules into the GO layers increases the $d$-spacing to a value of $10.34 \AA$ as the corresponding peak shifts to $2 \theta=8.6^{\circ}$ in the PXRD patterns of dried TAIPDI-GO hybrid gel (Fig. 3).

The free energy change of the proposed photoinduced charge separation $\left(\Delta G_{\mathrm{CS}}\right)$ in PDI-GO hybrid was calculated according to eqn $(1){ }^{7}$

$$
\Delta G_{\mathrm{CS}}=e\left(E_{\mathrm{ox}}-E_{\mathrm{red}}\right)-E_{\mathrm{S}}
$$

where $E_{\mathrm{Ox}}$ is the first oxidation potential of $\mathrm{GO}, E_{\mathrm{red}}$ is the first oneelectron reduction of PDI, and $E_{\mathrm{S}}$ is the lowest ${ }^{1} \mathrm{PDI}^{*}$, which was estimated to be $2.28 \mathrm{eV}$ from the absorption and emission spectra. The first oxidation of GO occurred at $0.88 \mathrm{~V} v$ s. SCE in water containing $0.10 \mathrm{M} \mathrm{Na}_{2} \mathrm{SO}_{4}$ as detected using cyclic and differential pulse voltammetry (Fig. S7, ESI $\dagger$ ). ${ }^{8}$ The first one-electron reduction of PDI was found to be $-0.25 \mathrm{~V} v$ s. SCE in water containing $0.10 \mathrm{M}$
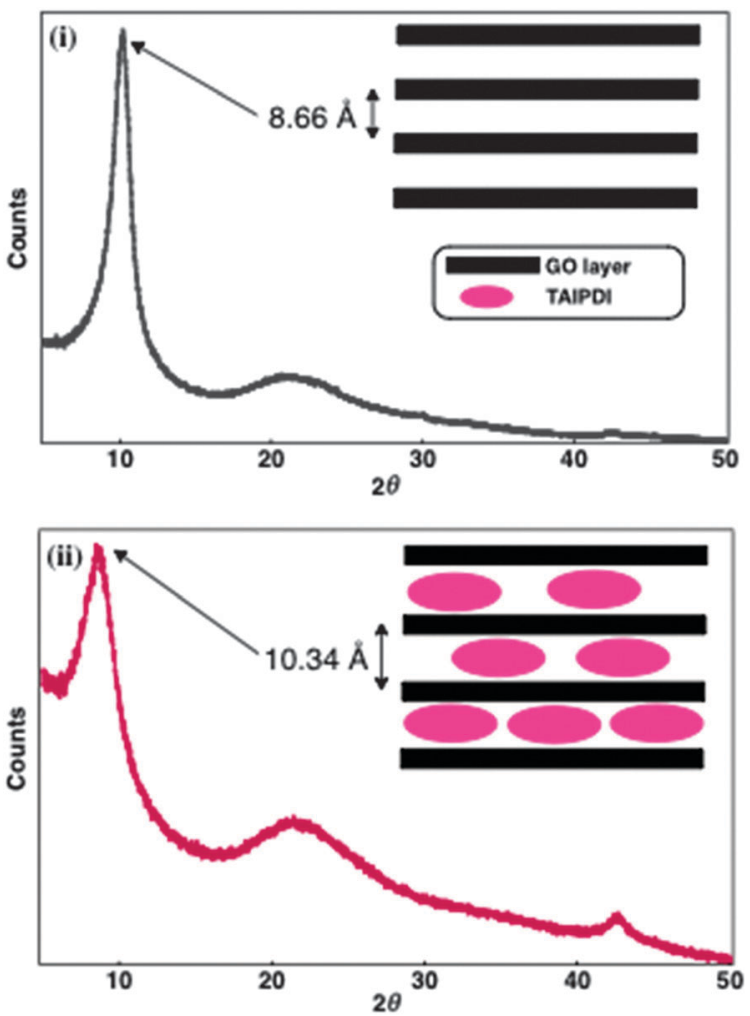

Fig. 3 Powder X-ray diffraction patterns of dried (i) GO and (ii) TAIPDI-GO supramolecular gel. Inset: representation of GO layers with and without TAIPDIs.

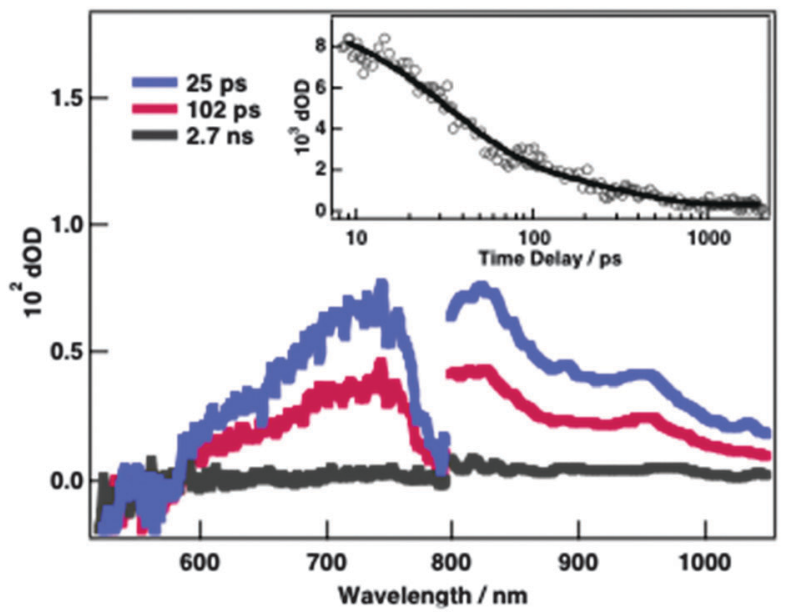

Fig. 4 Femtosecond laser-induced transient absorption spectra of $0.25 \mathrm{mM}$ TAIPDI and $0.6 \mathrm{mg} \mathrm{ml}^{-1} \mathrm{GO}$ in water at indicated time delays, $\lambda_{\text {exc }}=510 \mathrm{~nm}$. Inset: time profile at $720 \mathrm{~nm}$.

$\mathrm{Na}_{2} \mathrm{SO}_{4} \cdot{ }^{9}$ Hence, the photoinduced electron transfer from GO to ${ }^{1} \mathrm{PDI}^{*}$ is feasible via ${ }^{1} \mathrm{PDI}^{*}$ with a driving force of $1.15 \mathrm{eV}$.

Photoinduced electron-transfer dynamics of self-assemblies of PDI-GO hybrids were investigated by using femtosecond laserinduced transient absorption spectroscopy. The femtosecond transient spectra of aggregates of TAIPDI-GO (0.25 mM TAIPDI and $0.6 \mathrm{mg} \mathrm{ml}^{-1} \mathrm{GO}$ ) in water displayed a very fast formation of broad transient absorption at around 720 and $960 \mathrm{~nm}$ after the selective excitation of PDI at $510 \mathrm{~nm}$ (Fig. 4). These transient traits agree very well with those of the radical anion of PDI $\left(\mathrm{PDI}^{\bullet-}\right),{ }^{9,10}$ providing a valid proof for photoinduced electron transfer from GO to ${ }^{1} \mathrm{PDI}^{*}$. By fitting the increase of the transient absorption at $720 \mathrm{~nm}$ to a curve of an exponential function, the rate of charge separation $\left(k_{\mathrm{CS}}\right)$ was estimated to be $3.6 \times 10^{11} \mathrm{~s}^{-1}$ $(\tau=2.8 \mathrm{ps}$, Fig S8, ESI $\dagger)$. The fast formation rate suggests that the charge separation is very efficient, which rules out the other quenching mechanisms such as energy transfer. The decay at the same wavelength comprises two components, whose lifetime values are extracted by fitting to a sum of two decaying exponentials (Fig. 4, inset). The former component of the fitting curve gives a lifetime for the first charge recombination of $31 \mathrm{ps}\left(k_{\mathrm{CR} 1}=3.2 \times 10^{10} \mathrm{~s}^{-1}\right)$. The lifetime of the eventual charge-separated state is calculated from the latter component to be $417 \mathrm{ps}\left(k_{\mathrm{CR} 2}=2.4 \times 10^{9} \mathrm{~s}^{-1}\right.$, Fig. 4, inset). Such a two-component decay was also observed in the $\pi$-stacks of PDI hosting porphyrins via $\pi-\pi$ and electrostatic interactions in water. Slow decay accounted for the presence of the electron migration mechanism among the $\pi$-stacks of PDI. ${ }^{9}$

To view the effect of concentration of GO, it is increased to $0.9 \mathrm{mg} \mathrm{ml} \mathrm{m}^{-1}$ by maintaining the concentration of TAIPDI at $0.25 \mathrm{mM}$, which means a lower number of TAIPDI molecules is deposited between the GO layers. Consequently, the lifetime values of 21 and 400 ps were, respectively, obtained from the twocomponent decay at $720 \mathrm{~nm}$ (Fig. S9, ESI $\dagger$ ). The slight decline indicates that charge migration is mainly realized through the GO sheets whereas the contribution of TAIPDI molecules is limited. In the case of low concentrations of GO $\left(0.3 \mathrm{mg} \mathrm{ml}^{-1}\right)$ with $0.15 \mathrm{mM}$ TAIPDI, the first and second components of the decay at $720 \mathrm{~nm}$ give 
lifetimes for charge separation of 2.3 and 48 ps, respectively (Fig S10, $\mathrm{ESI} \dagger$ ). This can be explained by the lack of adequate supramolecular organization of TAIPDI and GO. The concentration change of the GO did not have a significant impact on the formation rates of charge separation.

To test the effect of self-assembly on the rates of charge separation, TAIPDI-GO was dispersed in an aqueous polyethylene glycol (PEG 200) solution, in which the gel formation was not observed under the same conditions $\left(\sim 0.6 \mathrm{mg} \mathrm{ml}^{-1} \mathrm{GO}\right.$ and $0.25 \mathrm{mM}$ TAIPDI). The femtosecond laser-induced transient absorption spectra of well-dispersed GO-PDI hybrids in the PEG 200 solution exhibited the excited state absorption peak at around $710 \mathrm{~nm}$ with bleaching at $550 \mathrm{~nm}$ after laser excitation at $510 \mathrm{~nm}$ (Fig. S11, ESI $\dagger$ ). These transient spectra match with those of ${ }^{1} \mathrm{PDI}^{*} .{ }^{9 a}$ The decay profile of absorbance at around $710 \mathrm{~nm}$ indicates that the lifetime of ${ }^{1} \mathrm{PDI}^{*}\left(\tau_{\mathrm{S}}\right)$ is remarkably reduced. There was no transient signal to be attributed to the electron-transfer products (i.e., the radical ion pair) probably because of rapid back electron transfer. ${ }^{10}$ The rate of charge separation of PDI-GO hybrids $\left(k_{\mathrm{CS}}\right)$ in the PEG 200 solution was estimated to be $2.3 \times 10^{9} \mathrm{~s}^{-1}$, which is significantly slower than that of the self-assembled form of TAIPDI-GO in neat water. ${ }^{11}$ As a result, the polymer chains of PEG 200 in the solution impede the supramolecular organization of TAIPDI-GO. Although the charge separation is not efficient no other transient trait was obtained to be assigned to the energy transfer mechanism in the femtosecond transient absorption spectra.

Formation of the charge-separated states in the selfassemblies of PDI-GO hybrids in aqueous media was verified by the electron paramagnetic resonance (EPR) measurements, in which the EPR spectrum of PDI ${ }^{\bullet-}$ displays a powder pattern without hyperfine splitting $(g=2.0041)$ in frozen media at $4 \mathrm{~K}$ after photoexcitation (Fig. S12, ESI $\dagger$ ).

The hole (i.e. radical cation) formed after the photoinduced charge separation is expected to easily migrate on the smooth $\pi$-surface of a graphene sheet, resulting in slower charge recombination despite the fact that the electron-transfer distance between non-covalently-functionalised, electron-donating graphene and the electron-accepting dye molecule is very close due to $\pi-\pi$ interactions. ${ }^{2 g, 12}$ In the case of PDI-GO dispersed in the solution of PEG 200, the fast charge recombination can be rationalized from the close distance between the electron donor and acceptor and the lack of the effective hole delocalization on the surface of the GO because of the defects on the honeycomb structure, ${ }^{13}$ resulting from the chemical oxidation. ${ }^{14}$ The presence of the functional groups on the GO sheet is practical for the non-covalent functionalisation of the GO by the dye molecules; however, they cause the interruption of the continuous conjugation of the $\pi$-surface. Despite the fact that the charge migration on the $\pi$-surface is severely inhibited by the defects it can be regenerated between the adjacent $\pi$-stacks of PDI-GO hybrid layers in the self-assemblies as indicated by the slow component of the decay time profile (Fig. 4, inset, Fig S9 and S10, ESI $\dagger$ ). Migration through the $\pi$-stacks is likely to promote a "pull effect" for fast charge separation. Dispersion of these hybrid stacks in a polymer environment seems to block such an interlayer charge-hopping mechanism due to the disruption of the supramolecular organization, causing the fast back electron transfer from $\mathrm{PDI}^{\bullet-}$ to oxidized GO.
In summary, non-covalent functionalisation of GO with visible light-absorbing PDI was achieved through the $\pi-\pi$ and electrostatic interactions in water. TAIPDI-GO hybrids reveal a supramolecular self-assembly as recognized by the PXRD patterns of gel formation in an aqueous environment. Our findings have demonstrated that $\pi$-stacking is necessary for fast charge separation and slow charge recombination, which is facilitated by an interlayer charge migration mechanism within the ordered self-assemblies of the PDI-GO hybrids during the photoexcitation.

This work was supported by Grant-in-Aid for Scientific Research (No. 266201541 and 26288037), an ALCA project from JST. M.S. thanks JSPS for a postdoctoral fellowship.

\section{Notes and references}

1 (a) D. Chen, H. Feng and J. Li, Chem. Rev., 2012, 112, 6027; (b) I. V. Lightcap and P. V. Kamat, Acc. Chem. Res., 2013, 46, 2235; (c) H. Chang and H. Wu, Energy Environ. Sci., 2013, 6, 3483; (d) Q. Tang, Z. Zhou and Z. Chen, Nanoscale, 2013, 5, 4541; (e) S. Naficy, R. Jalili, S. H. Aboutalebi, R. A. Gorkin III, K. Konstantinov, P. C. Innis, G. M. Spinks, P. Poulin and G. G. Wallace, Mater. Horiz., 2014, 1, 326.

2 (a) Q. Su, S. Pang, V. Alijani, C. Li, X. Feng and K. Müllen, Adv. Mater., 2009, 21, 3191; (b) A. Wojcik and P. V. Kamat, ACS Nano, 2010, 4, 6697; (c) J. Geng and H.-T. Jung, J. Phys. Chem. C, 2010, 114, 8227; (d) Z. D. Liu, H. X. Zhao and C. Z. Huang, PLoS One, 2012, 7, e50367, DOI: 10.1371/ journal.pone.0050367; (e) W. He, C.-E. He, R. Peng and Y. Yang, Adv. Mater. Res., 2012, 534, 118; $(f)$ N. Karousis, J. Ortiz, K. Ohkubo, T. Hasobe, S. Fukuzumi, Á. Sastre-Santos and N. Tagmatarchis, J. Phys. Chem. C, 2012, 116, 20564; $(g)$ K. Dirian, M. Á. Herranz, G. Katsukis, J. Malig, L. Rodriguez-Perez, C. Romero-Nieto, V. Strauss, N. Martín and D. M. Guldi, Chem. Sci., 2013, 4, 4335; ( $h$ ) S. Roy, D. K. Maiti, S. Panigrahi, D. Basak and A. Banerjee, Phys. Chem. Chem. Phys., 2014, 16, 6041.

3 S. Srinivasan, S. H. Je, S. Back, G. Barin, O. Buyukcakir, R. Guliyev, Y. Jung and A. Coskun, Adv. Mater., 2014, 26, 2725.

4 (a) F. Würthner, Chem. Commun., 2004, 1564; (b) M. R. Wasielewski, J. Org. Chem., 2006, 71, 5051; (c) M. Supur and S. Fukuzumi, ECS J. Solid State Sci. Technol., 2013, 2, M3051.

5 (a) M. Ohtani and S. Fukuzumi, Chem. Commun., 2009, 4997; (b) Z. Zhang, H. Huang, X. Yang and L. Zang, J. Phys. Chem. Lett., 2011, 2, 2897; (c) C. Bikram K. C., S. K. Das, K. Ohkubo, S. Fukuzumi and F. D'Souza, Chem. Commun., 2012, 48, 11859; (d) O. Ito and F. D'Souza, ECS J. Solid State Sci. Technol., 2013, 2, M3063.

6 The effect of cationic heads of PDI on binding was also tested. There was no shift in the absorption maxima of a PDI derivative with alkyl chains ( $N, N$ '-diheptadecan-9-ylperylenediimide, HHPDI) during the titration with GO (Fig. S5, ESI $\dagger$ ) and no gel formation was observed, which declares the need of cationic substituents for effective selfassembly. Besides, fluorescence quenching of HHPDI was incomplete when titrated with the same amount of GO as in the titration of PDI with cationic heads in water (Fig. S6, ESI $\dagger$ ).

7 A. Weller, Z. Phys. Chem., 1982, 133, 93.

8 It should be noted that the oxidation potential of GO can vary with the degree of oxidation of reactant graphite during the synthesis of GO, see: K. Krishnamoorthy, M. Veerapandian, K. Yun and S.-J. Kim, Carbon, 2013, 53, 38.

9 (a) M. Supur and S. Fukuzumi, J. Phys. Chem. C, 2012, 116, 23274; (b) M. Supur and S. Fukuzumi, Phys. Chem. Chem. Phys., 2013, 15, 2539.

10 M. Supur, Y. M. Sung, D. Kim and S. Fukuzumi, J. Phys. Chem. C, 2013, 117, 12438.

11 The rate of charge separation of PDI-GO hybrids $\left(k_{\mathrm{CS}}\right)$ in polymer solutions was estimated from the quenching of the singlet-excited states of PDI by using eqn: ${ }^{10} k_{\mathrm{CS}}=\left(1 / \tau_{\mathrm{q}}\right)-k_{\mathrm{S}}$ where $\tau_{\mathrm{q}}$ is the lifetime of quenched ${ }^{1} \mathrm{PDI}^{*}$ due to photoinduced electron transfer and $k_{\mathrm{S}}$ is the rate constant of ${ }^{1} \mathrm{PDI}^{*}$ without any quenching.

12 J. Malig, N. Jux and D. M. Guldi, Acc. Chem. Res., 2013, 46, 53.

13 F. Banhart, J. Kotakoski and A. V. Krasheninnikov, ACS Nano, 2011, $5,26$.

14 S. Stankovich, D. A. Dikin, R. D. Piner, K. A. Kohlhaas, A. Kleinhammes, Y. Jia, Y. Wu, S. T. Nguyen and R. S. Ruoff, Carbon, 2007, 45, 1558. 